amenable to treatment, especially when the chief part of the disability consists in spastic club-foot. Such cases give complete satisfaction to all concerned.

old Cavendish-street, $\mathrm{w}$.

\section{A CASE OF PUERPERAL ECLAMPSIA} SUCCESSFULLY TREATED BY CHLORAL AND BROMIDE OF POTASSIUM WITH INHALATION OF CHLOROFORM.

BI WILLIAM FREDERICK GARDENER, M.R C.S. ExG., L.R.C.P. LOND.

I WAS called on Dac. 6th, 1896, at 4.45 P.M., to see a woman who had engaged me to attend her in her confinewent about that date (Dec. 8th to 15 th). She was forty-one years of age, and this was her first pregnancy. On arrival I found her dressed and seeming very dull. It was said that she had been complaining of "her head" and suddenly went off into some kind of fit, her features being convulsed and blackened. The case seeming like puerperal eclampsia she was at once removed to bed. A soap-and-water enema had been given in the morning which had acted slightly. A.t 5.15 the patient was seized with a second fit, in all respects typical of puerperal eclampsia. Three grains of calomel were placed on the back of the tongue and followed by 20 grains each of chloral hydrate and bromide of potassium. Most of the calomel was swallowed and the whole of the mixture. at 5.50 a third convulsion occurred which was cut short by administration of chloroform vapour. At 6.50 3nother fit was similarly treated, the inhalation of chloroform being prolonged for the purpose of making a raginal examination. The os was found to be dilated to the diameter of a little less than half an inch At Bo'clock $\frac{1}{10}$ gr. pilocarpine hydrochlorate was injected subcutaneously. In response to repeated inquiries the patient complained of sickness. At 8.45 and 9.32 the fits recurred. By 9 P.M. the os had dilated very slightly. At 10.30 the patient commenced to moan, her eyes opened, and lateral nystagmus became visible with turning of the head and eyes to the left. A few whiffs of chloroform removed all these symptoms and staved off another convulsion, as in this way the previons ones had commenced. At $11.5 \mathrm{P}$. is and 22.55 A.M. the nystagmus returning convalsions were again prevented by a prophylactic use of chloroform. Every three hours a nutrient enema of beef-tea and milk was administered containing twenty grains each of bromide of potassium and chloral hydrate. At 9.15 P.M. urine had been passed into the bed and at 10.45 P.M. the bowels had commenced to act. At 2.25 A.M. on Dec. 7th a convulsive attack again seized the patient, the first not prevented since 9.32 the previous erening. At 4.25 A.M. the temperature was $103^{\circ}$ and the pulse was 108. At 10.20 the temperature was $100^{\circ}$ and the pulse 118 . At 12.30 P.M. the first specimen of urine was obtained, being drawn off by catheter; it was " portercoloured" and yielded five-sixths albumin. In consultation with Mr. Soltau Eccles, of Norwood, it was decided to leave the case to nature unless there should be any return of the convulsive seizures. The pains were then becoming fairly regalar and the os was very slowly dilating. There were no more fits. The mixture of bromide of potassium and chloral hydrate was given in small enemata of milk and beef tea every four hours. The pupils remained contracted, and the patient complained occasionally of great pain in the head, but the nystagmus and twitching of the muscles were absent and the bowels acted freely and often. By 4 o'clock the amount of albumin present had diminished to one-sixth, lessening slightly towards evening. At 11 o'clock the foetus was born without any very strong pains. It was stillborn, and had apparently been dead some days. At 2 A.M. on Dec. 8th the temperature had fallen to $994^{\circ}$, and at $80^{\prime}$ clock to $97 \cdot 2^{\circ}$. From this date to Dec. 19 th there was considerable variation of temperature from $97^{\circ}$ to $102^{\circ}$. The urine contained from one-tenth to one-eighth albumin up to this date, then slowly cleared off, till early in January only a very faint trace remained. Very severe headaches were present during the whole time, for which a variety of drugs were tried, ammonium chloride giving the best results.
A mixture of acid tartrate of potash and digitalis was given for some weeks, with $40 \mathrm{gr}$. of pulv. jalapæ co. at night.

The great interest in this case was the extraordinary ease with which the fits were arrested by chloroform inhalation. One hundred grains each of chloral hydrate and potassium bromide were retained by the mouth and rectum.

Sydenham.

\section{Clinital :}

\section{MEDICAL, SURGICAL, OBSTETRICAL, AND} THERAPEUTICAL.

NOTE ON A CASE OF TUBERCULOUS DISEASE OF THE BLADDER TREATED BY SUPRA-PUBIC CYSTOTOMY AND CURETTING.

By Edward CotTereli, F.R C.S. ENG., SURGEON TO OUTPATIENTS, LONDON IOCK HOSPITAL, \&C.

I wAs consulted in the spring of 1895 by a man aged thirty-two years who complained of great irritability of the bladder both by day and by night. There was pain in the hypogastric region, in the perineum, and in the middle of the penis during and after micturition, and occasionally there was stoppage of the stream. Now and then a few small clots of blood passed after micturition. These symptoms had been coming on for some ten or twelve months and were becoming gradually intensified. The patient was losing flesh ; he looked ill and altogether appeared to be in a very unsatisfactory state of health. The urine was alkaline, of specific gravity 1012, and contained a large amount of mucopus, but tubercle bacilli were no's detected in the deposit after centrifugalisation. The prostate was slightly tender, but was not nodular or perceptibly enlarged. The testicles were free from evidences of tuberculous disease. Cystoscopic examination showed that the bladder was markedly trabeculated, and a small ragged ulcer was detected just below the mouth of the right ureter. Upon June 23rd, 1895, I performed supra-pubic cystotomy and thoroughly curetted the ulceration, after which the raw surface was freely burnt with Paquelin's thermo-cautery. The after history of the case presented nothing unusual. The wound healed within a month, and the urine gradually became acid and free from pus and mucus. After the wound had healed the irritability of the bladder was found to have disappeared completely, but owing to the contracted state of the bladder micturition for some time was a little more frequent than is usually the case; but gradually this condition improved and approached the normal standard. In the following December the patient was apparently quite well. The urine was acid, with a specific gravity of 1028 . There was no irritability of the bladder by day or by night. There was no pain, and altogether the general as well as the local condition had much improved since he came under my care.

I am induced to add the notes of this case to those on the same subject which have previously appeared in THE LANCET as a further contribution to the modern surgical treatment of tuberculosis affecting the bladder. At the present time (S ptember, 1897) the patient is quite well in health. He has had no urinary symptoms or trouble whaterer since convalescence from the operation has been established, so that the case appears to promise well for the future.

West Halkin-street, s.W.

\section{NOTE ON A CASE OF DEATH FROM LIGHTNING STROKE.}

By C. F. GLINN, M.R.C.S. ENG., L R.C.P. LoNd.

ON April 28th, 1897, about 4 P.M., during a thunderstorm of unusual severity, I was called out to see a farmer, aged fifty-four years, who, it was stated, had apparently been struck dead by lightning about half an hour previously. On my arrival I found the man dead and lying on the kitchen floor, where he had been placed when brought in. I was told that at the commencement of the storm he had said to his wife that he would go out in the field just behind the house to 